VUV spectroscopy in impurity injection experiments at KSTAR using prototype ITER VUV spectrometer

C. R. Seon, , J. H. Hong, , I. Song, , J. Jang, , H. Y. Lee, , Y. H. An, , B. S. Kim, , T. M. Jeon, , J. S. Park, , W. Choe, , H. G. Lee, , S. Pak, , M. S. Cheon, , J. H. Choi, , H. S. Kim, , W. Biel, , P. Bernascolle, and, and R. Barnsley

Citation: Review of Scientific Instruments 88, 083511 (2017); doi: 10.1063/1.4998970

View online: http://dx.doi.org/10.1063/1.4998970

View Table of Contents: http://aip.scitation.org/toc/rsi/88/8

Published by the American Institute of Physics

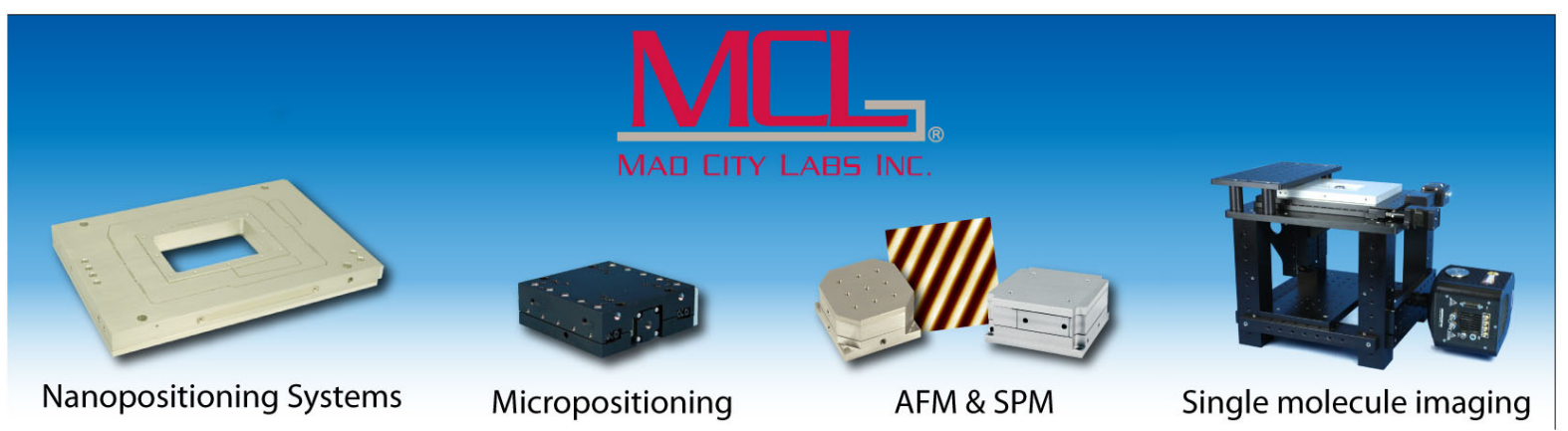




\title{
VUV spectroscopy in impurity injection experiments at KSTAR using prototype ITER VUV spectrometer
}

\author{
C. R. Seon, ${ }^{1, a)}$ J. H. Hong, ${ }^{2}$ I. Song, ${ }^{2}$ J. Jang, ${ }^{2}$ H. Y. Lee, ${ }^{2}$ Y. H. An, ${ }^{1}$ B. S. Kim, ${ }^{3}$ T. M. Jeon, ${ }^{2}$ \\ J. S. Park, ${ }^{2}$ W. Choe, ${ }^{2}$ H. G. Lee, ${ }^{1}$ S. Pak, ${ }^{1}$ M. S. Cheon, ${ }^{1}$ J. H. Choi, ${ }^{1}$ H. S. Kim, ${ }^{1}$ W. Biel, ${ }^{4}$ \\ P. Bernascolle, ${ }^{5}$ and R. Barnsley ${ }^{5}$ \\ ${ }^{1}$ National Fusion Research Institute, Gwahangno, 169-148 Yuseong-gu, Daejeon, South Korea \\ ${ }^{2}$ Korea Advanced Institute of Science and Technology, Daehak-ro, 291 Yuseong-gu, Daejeon, South Korea \\ ${ }^{3}$ Department of Energy Systems Research, Ajou University, Suwon 443-749, South Korea \\ ${ }^{4}$ Institut für Plasmaphysik, Forschungszentrum Jülich Gmbh, EURATOM Association, Trilateral Euregio Cluster, \\ D-52425 Jülich, Germany \\ ${ }^{5}$ ITER Organization, Route de Vinon-sur-Verdon - CS 90 046, 13067 Saint-Paul-lez-Durance, France
}

(Received 7 November 2016; accepted 30 July 2017; published online 18 August 2017)

\begin{abstract}
The ITER vacuum ultra-violet (VUV) core survey spectrometer has been designed as a 5-channel spectral system so that the high spectral resolving power of 200-500 could be achieved in the wavelength range of 2.4-160 nm. To verify the design of the ITER VUV core survey spectrometer, a two-channel prototype spectrometer was developed. As a subsequent step of the prototype test, the prototype VUV spectrometer has been operated at KSTAR since the 2012 experimental campaign. From impurity injection experiments in the years 2015 and 2016, strong emission lines, such as $\mathrm{Kr}$ xxv $15.8 \mathrm{~nm}, \mathrm{Kr}$ XxvI $17.9 \mathrm{~nm}, \mathrm{Ne}$ VII $46.5 \mathrm{~nm}, \mathrm{Ne}$ vI $40.2 \mathrm{~nm}$, and an array of largely unresolved tungsten lines (14-32 nm) could be measured successfully, showing the typical photon number of $10^{13}-10^{15}$ photons $/ \mathrm{cm}^{2} \mathrm{~s}$. Published by AIP Publishing. [http://dx.doi.org/10.1063/1.4998970]
\end{abstract}

\section{INTRODUCTION}

Vacuum ultra-violet (VUV) spectrometer in a magnetic confined fusion device plays the key role of monitoring impurity species with regard to machine protection and plasma performance. ${ }^{1,2}$ Identification of impurities in tokamak plasmas is possible using VUV spectrometer for emission lines in the range of $2.4-160 \mathrm{~nm}$ or X-ray spectrometer for lines in the range of $0.05-10 \mathrm{~nm}$. To fulfill the measurement requirement of impurity identification in an ITER tokamak (a nuclear facility, INB-174), VUV spectrometers with a relatively high spectral resolving power have been designed. ${ }^{3-5}$ In order to facilitate impurity monitoring with full coverage of core, edge, and divertor plasmas, ITER VUV spectrometers are equipped with three sub-systems located in different positions.

The ITER VUV core survey spectrometer was designed as a five-wavelength channel system so that a relatively high spectral resolving power $(\lambda / \Delta \lambda)$ ranging from 200 to 500 could be achieved in the broad wavelength range between 2.4 and $160 \mathrm{~nm}^{3}$ Collection optics using toroidal mirrors was optimized to relay VUV emission lines with a high throughput. Further, the relay optics was designed to minimize the entrance pupil in the diagnostic shield module (DSM) of the port plug.

To establish the optimal design of multi-channel spectrometer, a two-channel prototype spectrometer was first developed with channel No. $3(14.4-31.8 \mathrm{~nm})$ and channel No. 4 (29.0-60.0 nm) among five wavelength channels (2.4$160 \mathrm{~nm}){ }^{3}$ The absolute intensity calibration was performed

\footnotetext{
a) Author to whom correspondence should be addressed: crseon@nfri.re.kr.
}

in the laboratory using emission lines from a hollow cathode lamp, which is an absolutely calibrated source via the electron storage ring BESSY in Berlin. ${ }^{6-9}$

To evaluate the performance of the prototype spectrometer, it has been operated at KSTAR since the 2012 experimental campaign. From the measured spectra and the calibration curve, the line integrated emissivity profile of various impurity species has been derived. Two kinds of impurities are observed in KSTAR plasmas. One relates to intrinsic impurities, such as $\mathrm{C}, \mathrm{O}, \mathrm{Fe}$, and $\mathrm{He}$ from the materials of the first wall or residual cleaning gases. The other consists of intentionally injected species such as $\mathrm{Ar}, \mathrm{Kr}, \mathrm{Ne}$, and $\mathrm{W}$ for diagnostic purposes or impurity seeding experiment. ${ }^{10,11}$ All these impurity species could be monitored successfully at KSTAR using this VUV spectrometer. In addition, plasma performances in specific wall interaction events or impurity injection experiments could be investigated. In this paper, various impurity lines in different plasma conditions are reported, and a performance assessment of the ITER VUV core survey spectrometer is performed.

In Sec. II, the design of the ITER VUV core survey spectrometer is outlined. In Sec. III, the experimental setup of the VUV spectrometer is described. In Sec. IV, VUV spectra for various impurity species measured at KSTAR are discussed.

\section{ITER VUV CORE SURVEY SPECTROMETER}

To monitor impurity species at different positions within the plasma, three kinds of ITER VUV spectrometers are to be installed, as shown in Fig. 1(a). The VUV edge imaging spectrometer in upper port \#18 consists of one field mirror with cylindrical geometry, one collimating mirror with ellipsoidal 


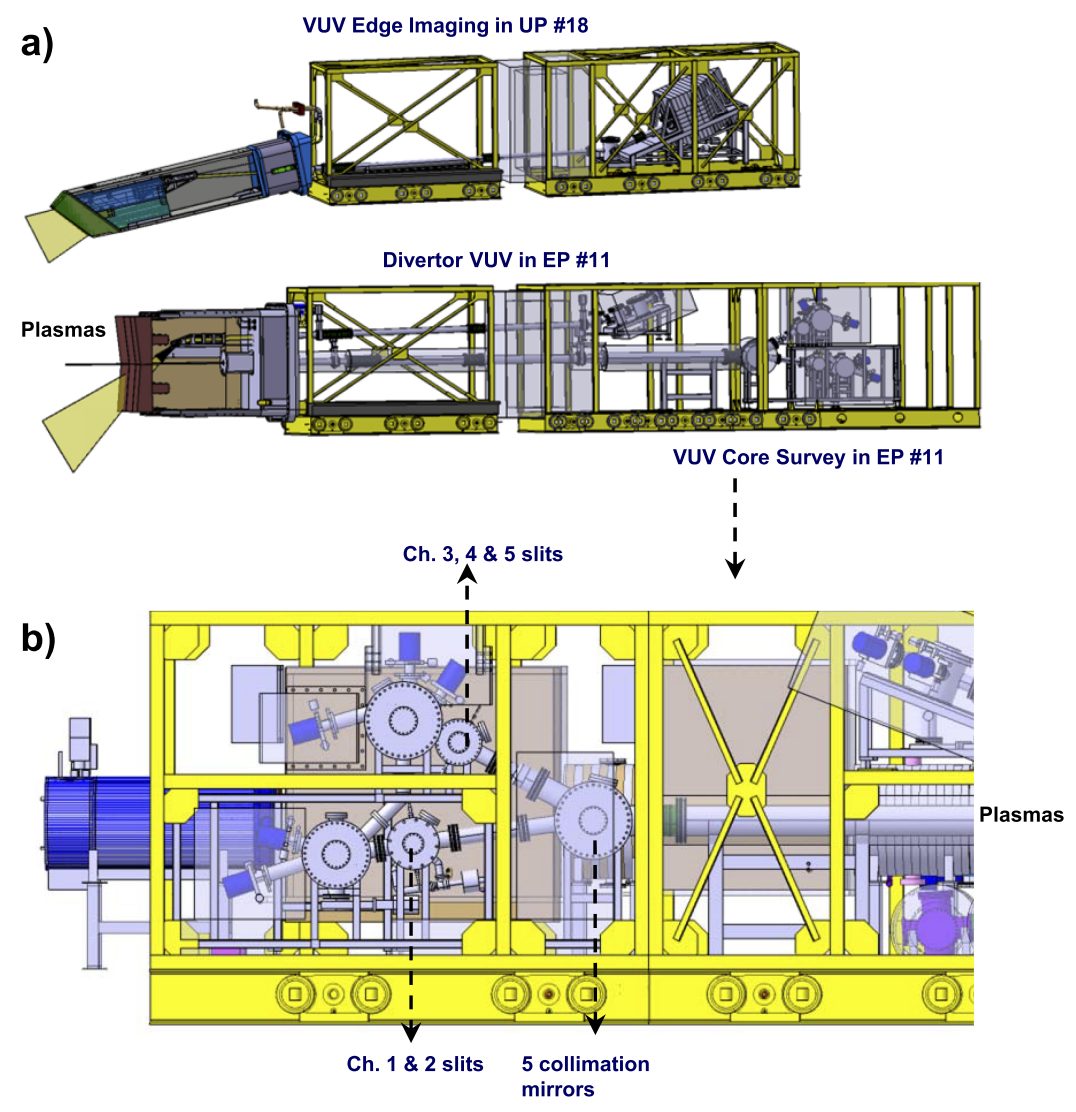

c)

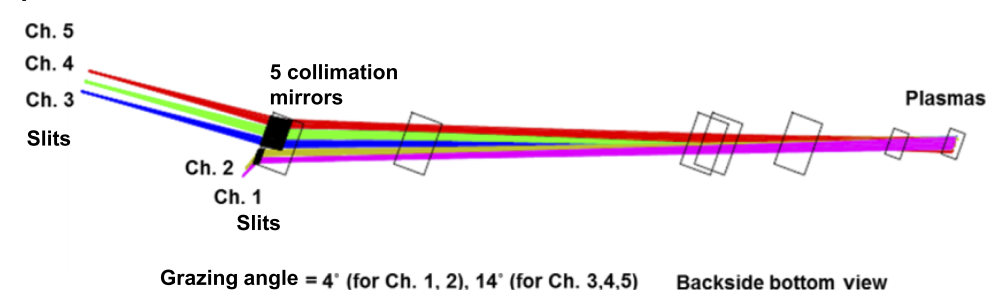

FIG. 1. (a) Total VUV spectrometers in ITER. (b) 5 channel VUV core survey spectrometer. (c) Backward ray tracing from slit to plasmas for VUV core survey spectrometer. geometry, and a VUV imaging spectrometer. ${ }^{12}$ The equatorial system in equatorial port \#11 employs a VUV survey spectrometer with five channels for wideband coverage and having high spectral and time resolution. The divertor VUV spectrometer is also located at equatorial port \#11 with relay optics consisting of a field mirror and a collimating mirror. The spectrometers and the collimating mirror systems are located in the port cell, i.e., outside the end of the port plug and also behind the biological shield as in the case of the JET VUV survey spectrometer. $^{13}$

The plasma-facing materials in ITER are berylliumcoated copper in the first wall and tungsten in the divertor. To achieve detached plasmas from the divertor, and possibly for diagnostic use, nitrogen or noble gases such as neon, argon, and krypton will be injected. Therefore, the most relevant impurities to be expected for ITER are Be (the first wall), O (naturally formed on $\mathrm{Be}$ wall), $\mathrm{Cu}$ (the structural material behind $\mathrm{Be}$ wall), $\mathrm{Fe}$ (retracted first wall for the diagnostic port), and $\mathrm{W}$ (the divertor) as well as $\mathrm{Ne}$, Ar, and $\mathrm{Kr}$ (seeded impurities). The characteristic spectral lines for Be ion identification are expected to be Be IV (7.59 nm, $6.07 \mathrm{~nm}, 41.00 \mathrm{~nm})$ and Be III $(10.03 \mathrm{~nm}, 8.83 \mathrm{~nm})$ from atomic data base. For oxygen ions in the VUV range, various measurements at tokamaks show strong lines of $\mathrm{O} v \mathrm{v}(17.3 \mathrm{~nm}, 18.4 \mathrm{~nm})$ and $\mathrm{O} v(19.28 \mathrm{~nm}$, $62.97 \mathrm{~nm}) .^{3,5}$ For iron, Fe xv (28.42 nm), Fe Xvi (33.54 nm, $36.08 \mathrm{~nm})$, and Fe XxIv (19.20 nm, $25.51 \mathrm{~nm})$ are expected, as reported in other tokamak machines. ${ }^{9,14}$ For copper ions, $\mathrm{Cu}$ XVIII $(23.42 \mathrm{~nm}), \mathrm{Cu}$ XIX $(27.34 \mathrm{~nm}, 30.36 \mathrm{~nm})$, and $\mathrm{Cu}$ XXVII $(15.36 \mathrm{~nm}, 22.48 \mathrm{~nm})$ are expected, as observed. ${ }^{14}$ In the case of tungsten, an array of lines in the range of 4-7 $\mathrm{nm}$ in the ITER plasma edge or core region and largely unresolved lines in the 14-32 $\mathrm{nm}$ range for the ITER plasma edge (near the last closed flux surface) region are expected to be observed. ${ }^{15} \mathrm{~A}$ few tungsten lines in the range 12-14 $\mathrm{nm}$ were reported to be originating from $\mathrm{W}^{40+}-\mathrm{W}^{44+}$ charge states in the ASDEX-U tokamak. ${ }^{15}$

The main role of the ITER VUV core survey spectrometer is designated as the line identification of all relevant impurity ions in main plasmas. To identify spectral lines in the target impurity mixture, a spectral resolving power between 200 and 500 is desirable for the $2.4-160 \mathrm{~nm}$ wavelength range. To achieve this goal, the VUV core survey spectrometer consisting of five channels $(2.4-7.7 \mathrm{~nm}, 7.2-16 \mathrm{~nm}, 14.6-32$ $\mathrm{nm}, 29.7-59 \mathrm{~nm}$, and $56-160 \mathrm{~nm}$ ) is located in two different 
sets of chambers, as shown in Fig. 1(b). The etendue for the 5-channel spectrometers varies from 0.4 to $1 \mathrm{~cm}^{2}$ sr. A holographic diffraction grating with toroidal geometry is used. ${ }^{5}$ As detectors, direct illumination CCDs of pixel size $16 \mu \mathrm{m}$ and head of $27.6 \mathrm{~mm} \times 6.9 \mathrm{~mm}$ size for survey spectrometer and $27.6 \mathrm{~mm} \times 12 \mathrm{~mm}$ size for imaging spectrometer are used. For the divertor VUV spectrometer, a CCD with head size $27.6 \mathrm{~mm} \times 6.9 \mathrm{~mm}$ is used. The five spectrometers of VUV core survey system are positioned in two sets of chambers with spatial shift of 20-50 mm between neighboring channels. In one set of chambers, two spectrometers (\#1 and \#2) are located and the remaining three (\#3, \#4, and \#5) are in the other one. Within the boundary of arrangement, the spectrometer design was optimized to yield high spectral resolving power and to minimize interference between detectors.

The vacuum ultraviolet light is collected using toroidal mirrors through a $\sim 28 \mathrm{~mm}$ height and $\sim 90 \mathrm{~mm}$ wide slot opening at the Diagnostic Shield Module (DSM). In one common mirror chamber, five mirrors are located, and they collimate VUV light to five slits of each spectrometer through the long vacuum extension pipe. The arrangement of mirrors avoid direct viewing that helps to reduce the radiation fluxes and neutron streaming effects at the spectrometer location. The requirement of the relay optics is that the mirror reflectivity needs to be higher than about $30 \%$ for each spectrometer channel considering sensitivity. F-number of each mirror needs to be the same as the f-number of the corresponding spectrometer. Simultaneously, the slot opening in DSM of the port plug needs to be minimized to reduce direct neutron streaming to protect detectors and to minimize activation of structural materials by neutrons.

To fulfill these requirements, the geometry of five collimating mirrors was chosen to be toroidal. From the mechanical boundary of the neighboring system, the grazing angle $(90-\alpha)$ to the collimating mirror was chosen to be $4^{\circ}$ and $14^{\circ}$, and the distance between the collimating mirror and the slit is $1200 \mathrm{~mm}$ as shown in Fig. 1(c). The gratings are positioned with different height, and the distance of adjacent gratings is about $20 \mathrm{~mm}-50 \mathrm{~mm}$ (center-to-center). The distance between the plasma and a mirror set \#1, \#2, or the remaining mirror set \#3, \#4, \#5 is $\sim 13400 \mathrm{~mm}$ (for \#1, \#2) or $\sim 13200 \mathrm{~mm}$ (for \#3, \#4, \#5).

Figure 1(c) shows the backward ray tracing result from the slit to the end of DSM using ray tracing software, ZEMAX. The backward ray bundles from a rectangular source array at the slit go to the collimating mirrors and reach the plasma region. By adjusting the radius of curvatures of the collimating toroidal mirrors, the size of the ray bundles was made to be as small as possible. From this optimizing process, the smallest foot print image in the DSM region is found to be about $60 \mathrm{~mm}$ $\times 23 \mathrm{~mm}$, and this implies that the slot opening size through DSM could be made to be around $60 \mathrm{~mm} \times 23 \mathrm{~mm}(\mathrm{w})$. We designed about $5 \mathrm{~mm}$ marginal space surrounding beam line, so the DSM slot opening size is ranged from $82 \mathrm{~mm} \times 28 \mathrm{~mm}$ (at the first wall side) to $94 \mathrm{~mm} \times 27 \mathrm{~mm}$ (at the back of DSM). In addition, the gate valve at the end of port plug can have about $100 \mathrm{~mm}$ inner diameter, and the tube diameter located between the first mirror and the collimating mirror can be about $200 \mathrm{~mm}$.

\section{EXPERIMENTAL SETUP AT KSTAR}

To validate the design of the ITER VUV core survey spectrometer, the prototype spectrometer with channel No. 3 and channel No. 4 has been developed and tested since the year 2010. The prototype ITER VUV spectrometer consists of a collimating mirror set, two holographic diffraction gratings with toroidal geometry, and two different electronic detectors, as shown in Fig. 2(a). ${ }^{4}$ A common slit with $10 \mathrm{~mm} \times 114 \mu \mathrm{m}$ size was used for each spectrometer. Two different detectors of the micro-channel plate (MCP) electron multiplier with camera (McPherson, Co.) and the back-illuminated charge coupled device (Princeton Instruments, Co.) are tested for channel No. $3(14.6-32 \mathrm{~nm})$ and channel No. $4(29.7-59 \mathrm{~nm})$, to compare detector performance. As described in Ref. 3, the spectral resolution of the $30.4 \mathrm{~nm} \mathrm{He}$ II line is $0.05 \mathrm{~nm}$ with backilluminated CCD, while the resolution of the $30.4 \mathrm{~nm} \mathrm{He}$ II line with the MCP detector is $0.08 \mathrm{~nm}$ in the same experimental condition and the same channel. The reason for the higher spectral resolving power of the back-illuminated CCD is due to that $\mathrm{MCP}+$ phosphor+camera gives about $80 \mu \mathrm{m}$ instrumental width due to gap between components, while the back-illuminated CCD with pixel size $13.5 \mu \mathrm{m}$ detects light directly on the sensor. The back-illuminated CCD provided efficiency of 35\%-43\% for the VUV light, while MCP showed an efficiency of $12 \%$ in the laboratory experiments. ${ }^{9}$

The calibrated hollow cathode lamp of Fig. 2(a) was used for the intensity calibration of the spectrometer as described in Ref. 9. The discharge condition of the hollow cathode lamp is $\mathrm{I}(\mathrm{DC}$ current $)=1-2 \mathrm{~A}$, DC voltage $=400-500 \mathrm{~V}$ with $\mathrm{He}$ or $\mathrm{Ne}$ as a discharge gas. The photon number incident on the slit of the emission line was divided by the measured detector counts and the spectrometer etendue to calculate the inverse sensitivity. The inverse sensitivity of the spectrometer, $p^{-1}$ [photons/(counts $\cdot \mathrm{mm}^{2} \mathrm{sr}$ )], is given as

$$
p^{-1}=P /(S \cdot \text { etendue })
$$

where $P$ (photons/s) is the photon number per a second passing through the slit, $S$ (counts/s) is the signal count rate for each emission line on the detector, and etendue $\left(\mathrm{mm}^{2} \mathrm{sr}\right)$ is the multiplication of the solid angle of the grating (sr) and the slit area $\left(\mathrm{mm}^{2}\right)$.

The photon number passing through the slit, $P$, was calculated based on the known emission power per solid angle for each spectral line in Ref. 6. To calculate $P$, the illuminated area on the slit position was investigated from the ray-tracing calculation. ${ }^{9}$ [Figure 2(a)] Intensity distribution on the illuminated area is found to be uniform from this ray-tracing calculation. For this reason, $P$ can be derived from the multiplication of the incident photon numbers on the slit position by (the slit area/the illuminated area), as shown in Fig. 2(a). The detector counts $\mathrm{S}$ of the back-illuminated CCD Ch. 4 were measured for each emission line. From Eq. (1), the inverse sensitivity $\mathrm{p}^{-1}$ of the channel No. 4 spectrometer could be derived. The error of the calibration points is about $30 \%$ (the back-illuminated CCD detector counts $15 \%$, the ray tracing error $15 \%$, and the hollow cathode lamp discharge condition instability 15\%). The calibration of the Ch. 3 spectrometer could be done from 

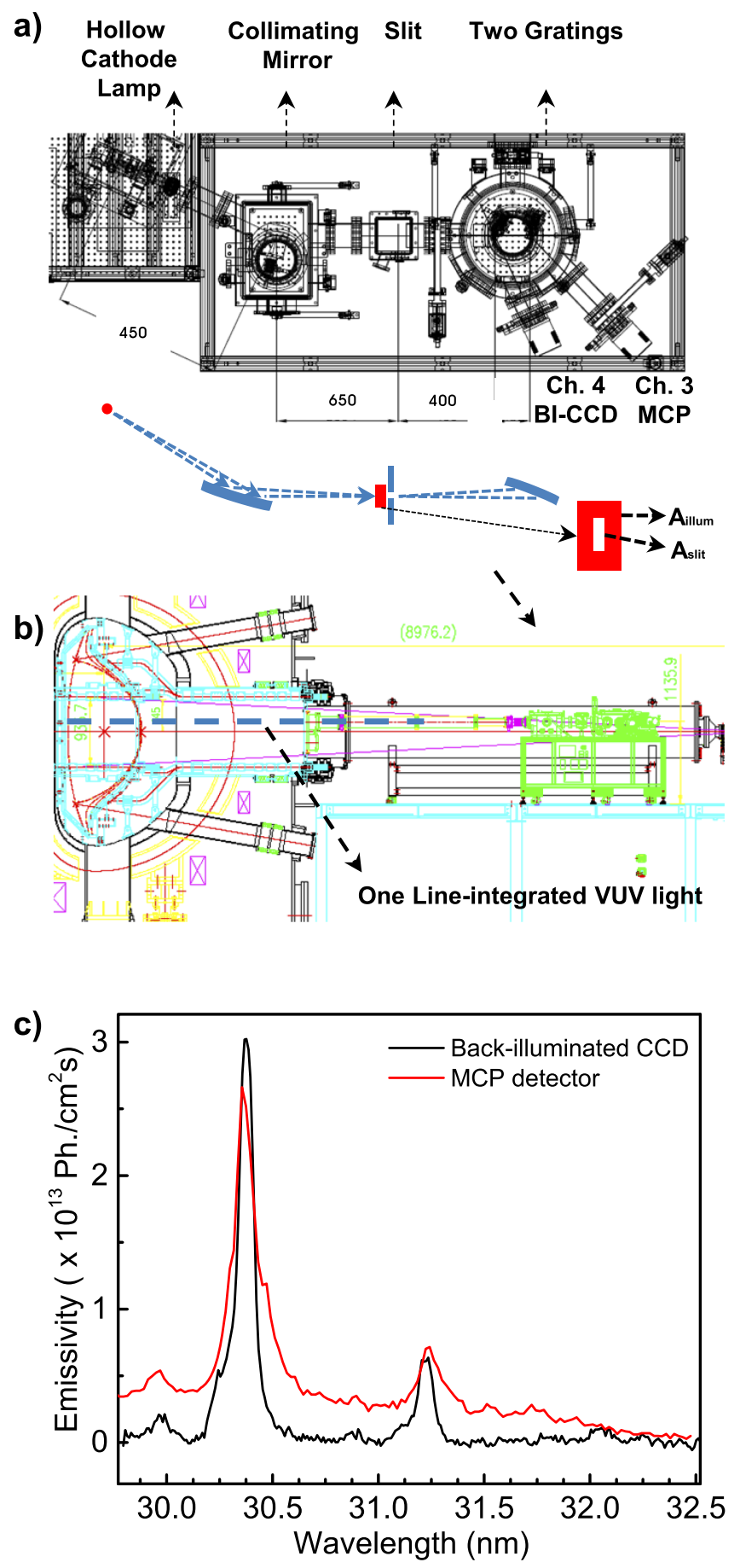

FIG. 2. (a) The VUV spectrometer prototype system. A collimation mirror, two gratings, and two different detectors were installed. Hollow cathode lamp was used for calibration. (b) The VUV spectrometer prototype system at KSTAR. (c) Comparison of spectral resolution between the back-illuminated CCD (black) and the MCP detector (red) for spectra measured in the KSTAR plasma.

the cross calibration using the overlapped wavelength range around $29-32 \mathrm{~nm}$.

The sensitivity curve of the spectrometer can also be obtained by multiplying the detector efficiency ranging from 0.35 to 0.43 and the grating efficiency ranging from 0.75 to 0.11. ${ }^{16-18}$ This expected calibration curve from the efficiency calculation showed relatively good agreement with the experimental result as described in Ref. 9. This result implies that the calculated efficiencies of optical components are accurate within an error of $30 \%$.

As a subsequent step of the prototype test, this prototype VUV spectrometer was installed at KSTAR. The VUV spectrometer is located at \#F port of KSTAR, and it measures line integrated light through a $3 \mathrm{~m}$ long vacuum extension pipe as shown in Fig. 2(b). The line of sight is $14 \mathrm{~cm}$ upward from the plasma center on the poloidal plane. To fit the mirror system to the KSTAR, a different collimation mirror set from the laboratory experiment was implemented. The mirror set composed of the attachment of one concave mirror and one cylindrical mirror collimates light from the plasma at a distance of $6 \mathrm{~m}$. Because a different mirror was used at KSTAR from the mirror used in the laboratory experiment, the calculated calibration curve was used for the analysis of the data obtained at KSTAR. The mirror reflectivity of the gold coated mirror set with surface roughness $4 \mathrm{~nm}$ and grazing angle $15^{\circ}$ was derived to be about $33 \%$ for $15-50 \mathrm{~nm}$ range from the calculation. From the mirror reflectivity, the grating efficiency, and the detector efficiency, a calibration curve of the VUV spectrometer was derived for the KSTAR experiment.

Figure 2(c) shows the measured spectra in the overlapped wavelength region of channel No. 3 with the MCP detector and channel No. 4 with the back-illuminated CCD detector from the KSTAR tokamak plasma. The back-illuminated CCD showed higher spectral resolution than the MCP detector in the tokamak experiment also. However, the spectral resolution of the channel No. \#4 spectrometer is about $0.1 \mathrm{~nm}$, and this resolution is worse that the $0.05 \mathrm{~nm}$ resolution in the laboratory experiment. The reason of this discrepancy is that the full area of the grating is illuminated by the light from KSTAR plasmas, while the grating area is partly illuminated by the point light source with $3 \mathrm{~mm}$ aperture in the laboratory experiment.

\section{VUV SPECTROSCOPY AT KSTAR}

The two-channel prototype ITER VUV spectrometer has been operated at KSTAR so that various impurity species could be identified from KSTAR plasmas. From various shots, the typical impurity emission lines of Fe xvI, Fe xv, He II, C Iv, Ar xv, Ar xvI, O v, and O vi could be identified, as shown in Fig. 3. The line integrated emission intensity was derived from the calibration curve, and the emission intensity of the $\operatorname{Ar}$ XVI $(35.4 \mathrm{~nm})$ line was about $0.2-5 \times 10^{15}$ photons $/ \mathrm{cm}^{2} \mathrm{~s}$ for typical shots.

It is important to evaluate the performance of this spectrometer with regard to the assessment of the ITER VUV core survey spectrometer. The detectable photon number (emissivity) of a spectrometer can be derived from the formula of sensitivity calculation for the spectrometer. From the optical design and the detector efficiency, the sensitivity of the total system is calculated with the following formula:

Detector_count_rate $=$ Line_integrated_emissivity $/ 4 \pi \times$

Etendue $\times$ Mirror_reflectivity $\times$ Grating_efficiency $\times$

Detector_efficiency.

For 100 photon counts in $10 \mathrm{~ms}$ to meet the ITER measurement requirement, we need a photon count rate of 
a)

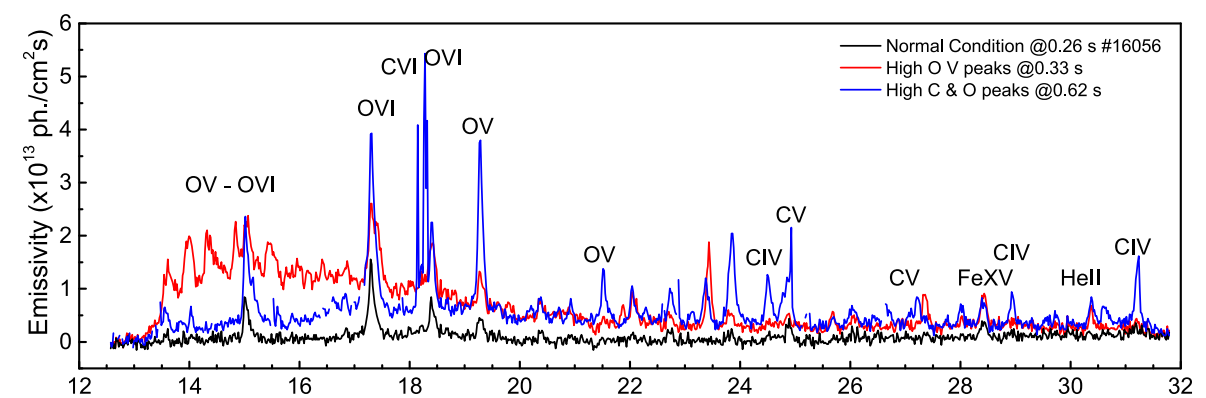

b)

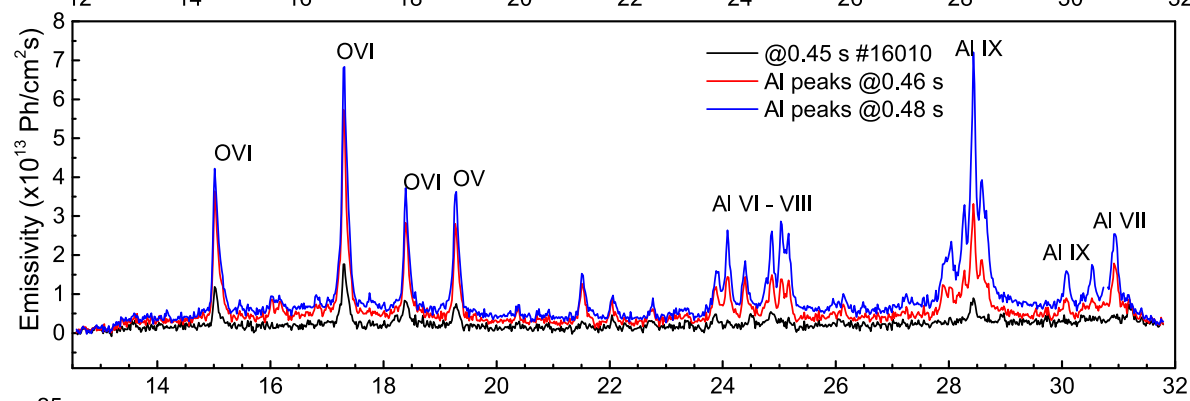

c)

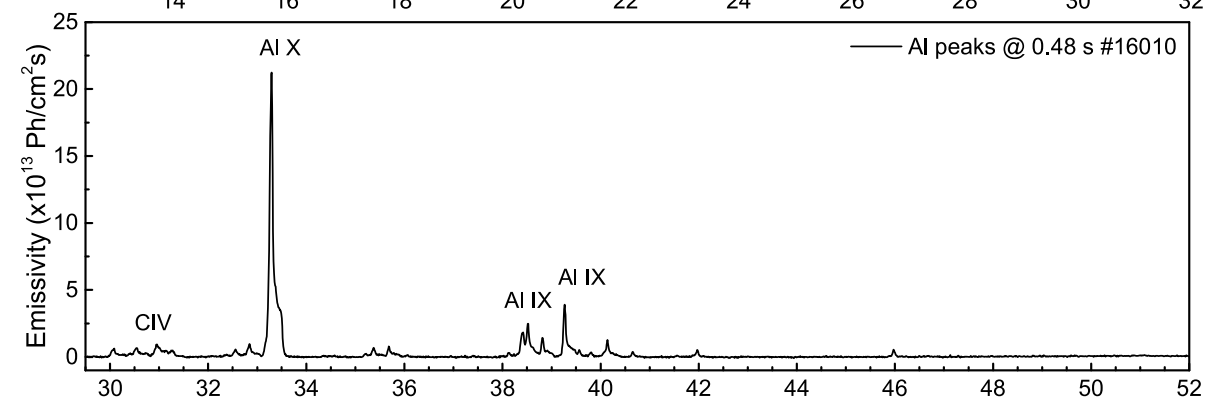

d)

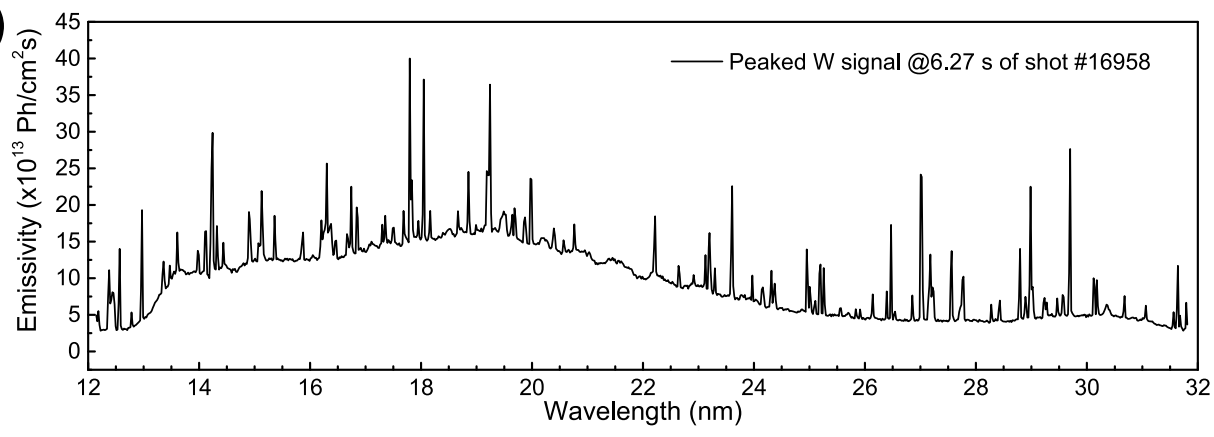

FIG. 3. (a) VUV spectra during the start-up phase at KSTAR shot \#16056. Different $\mathrm{C}$, $\mathrm{O}$ lines could be obtained depending on the plasma condition. [(b) and (c)] VUV spectra during the start-up phase at the $\mathrm{Al}$ particles injection event. (d) VUV spectra in tungsten powder injection experiment.
Count_rate $=10$ 000. Consequently, the required emissivity of the emission line to be detected is about line_integrated_emissivity $\sim 10000 \times 4 \pi /\left(2.2 \times 10^{-8}\right)=5.7$ $\times 10^{12}$ photons $/ \mathrm{cm}^{2} \mathrm{~s}$ from the calculation with values in Table I.

From the prototype test at KSTAR, the design of the ITER VUV core survey spectrometer could be verified because it was possible to detect emissivity of $\sim 5.0 \times 10^{12}$ photons $/ \mathrm{cm}^{2} \mathrm{~s}$ for VUV lines at KSTAR.

TABLE I. Optical parameter of the ITER VUV core survey spectrometer.

\begin{tabular}{ll}
\hline \hline Parameter & Designed value \\
\hline Spectrometer etendue & $1 \times 10^{-6} \mathrm{~cm}^{2} \mathrm{sr}$ \\
Reflectivity of mirror & 0.55 \\
Grating efficiency & 0.1 \\
Detector efficiency & 0.4 \\
Product $(\times)$ calculation of above terms & $2.2 \times 10^{-8}$ \\
\hline
\end{tabular}

Figure 3(a) shows an example of various intrinsic impurity lines at KSTAR. Various oxygen lines appear and disappear as the discharge time goes on. For example, $\mathrm{O} v$ lines around $15 \mathrm{~nm}$ appeared at $0.3 \mathrm{~s}$, but it was decreased at $0.6 \mathrm{~s}$ in \#16056 shot. However, intensity of the $\mathrm{O} v$ line $19.4 \mathrm{~nm}$ increased at $0.6 \mathrm{~s}$ compared to $0.3 \mathrm{~s}$, which is an opposite behavior to $\mathrm{O} v$ lines around $15 \mathrm{~nm}$. The electron temperature and density at $0.3 \mathrm{~s}$ and $0.6 \mathrm{~s}$ (start-up phases) in the plasma core are about $0.4-1 \mathrm{keV}$ and $0.5-1.6 \times 10^{19} / \mathrm{m}^{2}$, respectively. The reason for these unexpected lines is related to the fact that the electron temperature and the plasma density at the plasma edge region, where the VUV emission is occurring, are fluctuated. From Thomson scattering data, the electron temperature and the plasma density at the pedestal edge region were found to be highly fluctuating in this plasma shot.

In the case of special plasma interaction with some structural material like \#16010 shot, aluminum lines from $\mathrm{Al}$ vI to $\mathrm{Al} \mathrm{x}$ could be identified. Plasma interaction with the 
a)

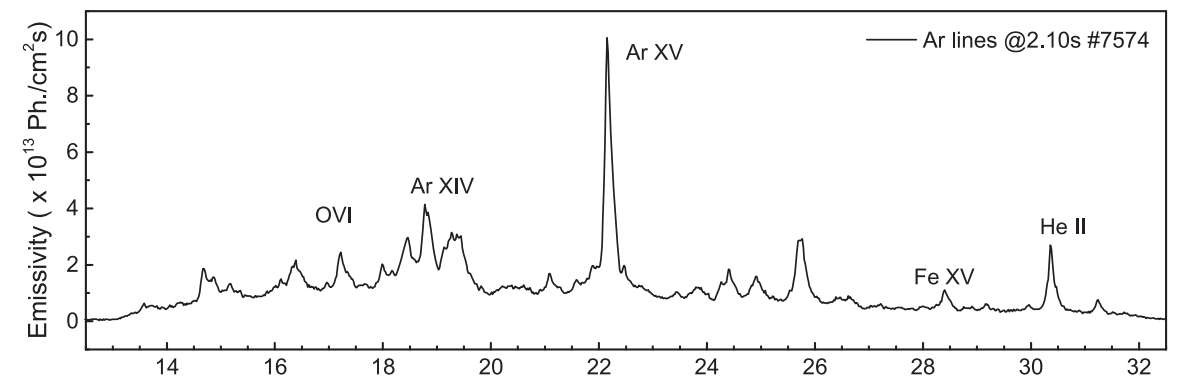

b)

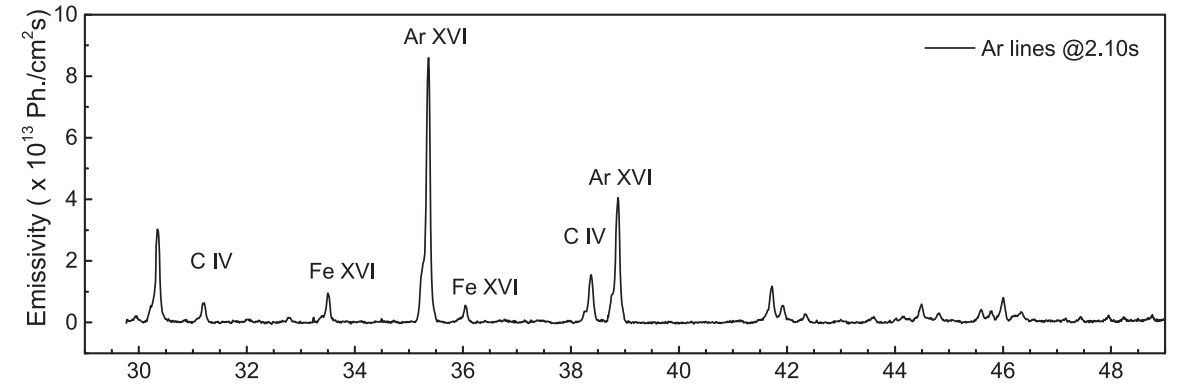

c)

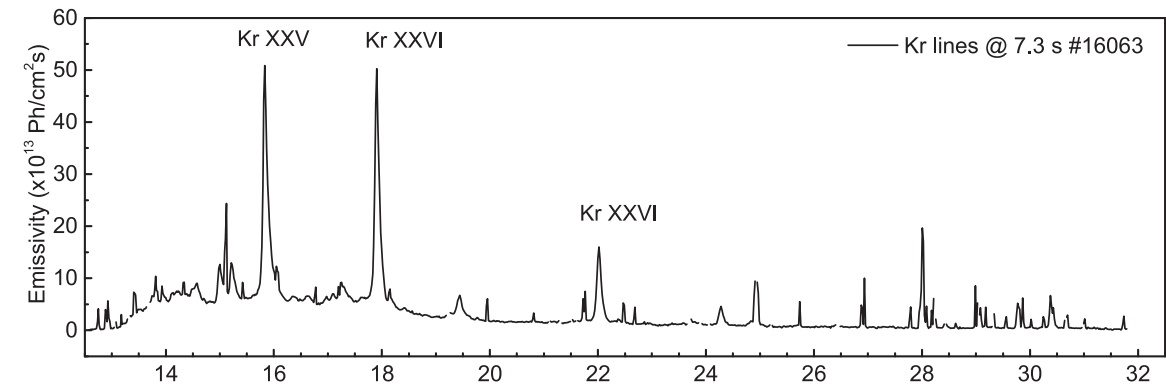

d)

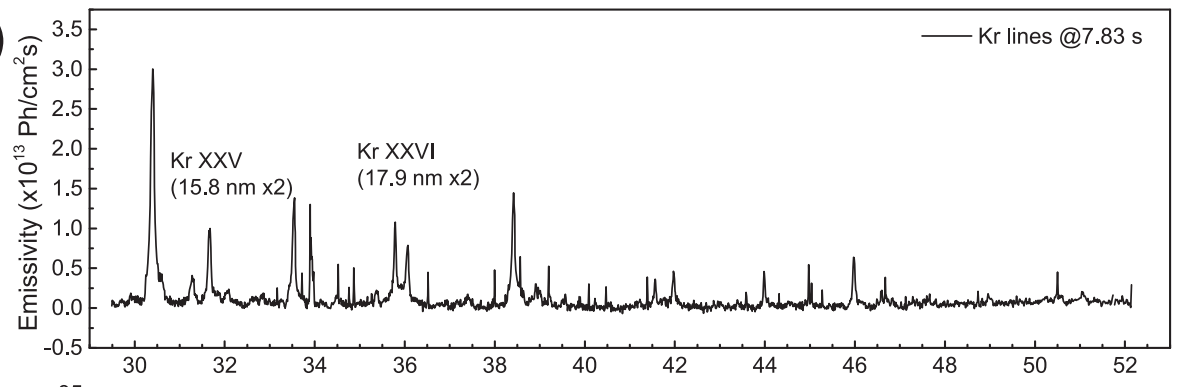

e)

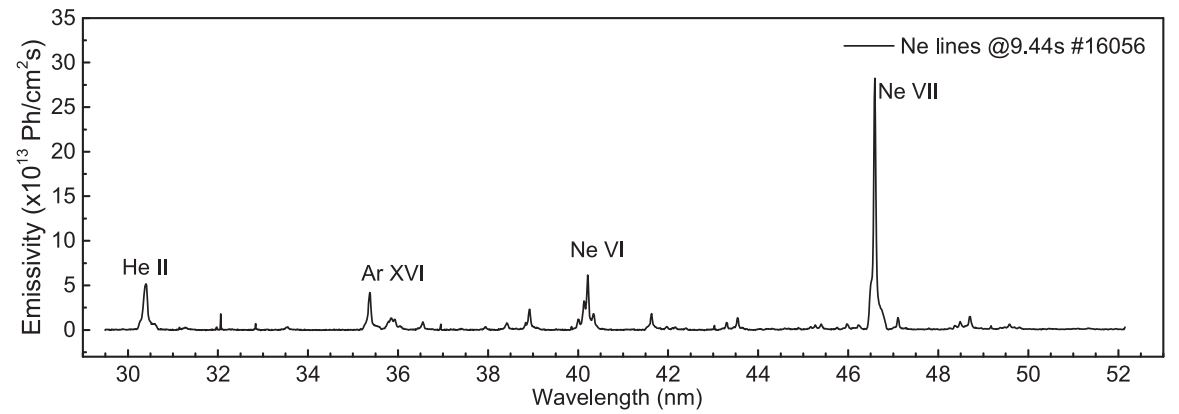

FIG. 4. [(a) and (b)] VUV spectra for Ar puffing experiment at KSTAR shot \#7574. Argon gas was puffed at $2.0 \mathrm{~s}$ for $20 \mathrm{~ms}$. [(c) and (d)] For Kr puffing experiment at KSTAR shot \#16063. (e) VUV spectra for Ne puffing experiment at KSTAR shot \#16056. aluminum (or ceramic) structure could also be observed with a visible camera image for \#16010 shot.

Inert gases like argon are used for diagnostic purpose and impurity seeding at KSTAR. ${ }^{11}$ Especially, argon has been used as a tracer gas for X-ray diagnostics at KSTAR, so argon lines can be detected very often in KSTAR plasmas, as shown in Figs. 4(a) and 4(b). The small shoulder of the spectral lines in Fig. 4(b) is due to the feature of the focusing, and a sharper line can be obtained by installing aperture to reduce the solid angle. To further study emission lines of high $\mathrm{Z}$ (atomic number) impurity ions at KSTAR, gas lines for neon, krypton, and tungsten dust injector systems were installed at KSTAR in 2014-2015. From the krypton injection experiments such as \#16063 shot, a $\mathrm{Kr}$ xxv line of $15.8 \mathrm{~nm}$ and a Kr xxvi line of $17.9 \mathrm{~nm}$ could be measured from the VUV spectrometer as shown in Fig. 4(c). The second order lines of $\mathrm{Kr}$ xxv $15.8 \mathrm{~nm}$ $\times 2=31.6 \mathrm{~nm}$ and $\mathrm{Kr}$ Xxvi $17.9 \mathrm{~nm} \times 2=35.8 \mathrm{~nm}$ also could be identified [Fig. 4(d)].

From the $\mathrm{Ne}$ injection experiments, $\mathrm{Ne}$ vII, $\mathrm{Ne}$ vi lines of $46.5 \mathrm{~nm}, 40.2 \mathrm{~nm}$ could be measured using the VUV 
spectrometer [Fig. 4(e)]. For a wavelength range of 15-30 nm, no strong Ne lines could be found at KSTAR. Weak Ne lines in $15-30 \mathrm{~nm}$ range were hard to be identified due to line blending by strong oxygen lines.

\section{CONCLUSION}

In this work, the ITER VUV core survey spectrometer design was introduced. It employs a five wavelength channel system in two sets of chambers. To verify the design, the twochannel prototype ITER VUV spectrometer was developed, and each spectrometer was absolutely calibrated. For the application of the calibrated prototype ITER VUV spectrometer, the prototype spectrometer has been operated at KSTAR. Various impurity lines such as, $\mathrm{C}, \mathrm{O}, \mathrm{Al}, \mathrm{Ne}$, and $\mathrm{Kr}$ were identified in different plasma conditions including the start-up phase. The feasibility of the ITER VUV core survey spectrometer could be evaluated from the prototype test at KSTAR. The expected emission lines in ITER such as tungsten and oxygen could also be measured at KSTAR.

\section{SUPPLEMENTARY MATERIAL}

See supplementary material for the design of the ITER VUV edge imaging spectrometer.

\section{ACKNOWLEDGMENTS}

This work has been supported by the Ministry of Science, ICT and Future Planning of the Republic of Korea under the Korean ITER project contract and National R\&D program
(No. 2014M1A7A1A03045092) of the National Research Foundation of Korea.

${ }^{1}$ S. Morita and M. Goto, Rev. Sci. Instrum. 74, 2036 (2003).

${ }^{2}$ W. Biel, R. Barnsley, and G. Bertshinger, in Proceedings of 31st EPS Conference (EPS, London, 2004), Vol. 28G, p. 1.134.

${ }^{3}$ C. R. Seon, S. H. Choi, M. S. Cheon, S. Pak, H. G. Lee, W. Biel, and R. Barnsley, Rev. Sci. Instrum. 81, 10E508 (2010).

${ }^{4}$ S. Varshney, R. Barnsley, M. G. O'Mullane, and S. Jakhar, Rev. Sci. Instrum. 83, 10E126 (2012).

${ }^{5}$ W. Biel, A. Greiche, R. Burhenn, E. Jourdain, and D. Lepere, Rev. Sci. Instrum. 77, 10F305 (2006).

${ }_{6}^{6}$ K. Danzmann, M. Günther, J. Fischer, M. Kock, and M. Kühne, Appl. Opt. 27, 4947 (1988).

${ }^{7}$ J. Hollandt, M. Kühne, and B. Wende, Appl. Opt. 33, 68 (1994).

${ }^{8}$ A. Greiche, W. Biel, O. Marchuk, and R. Burhenn, Rev. Sci. Instrum. 79, 093504 (2008).

${ }^{9}$ C. R. Seon, J. H. Hong, J. Jang, S. H. Lee, W. Choe, H. H. Lee, M. S. Cheon, S. Pak, H. G. Lee, W. Biel, and R. Barnsley, Rev. Sci. Instrum. 85, $11 \mathrm{E} 403$ (2014).

${ }^{10}$ H. Y. Lee, S.-H. Hong, J. Hong, S. H. Lee, S. Jang, J. Jang, T. Jeon, J. S. Park, and W. Choe, Rev. Sci. Instrum. 85, 11D862 (2014).

${ }^{11}$ J. Hong, S. H. Lee, J. Kim, C. R. Seon, S. G. Lee, G. Y. Park, K. D. Lee, S. S. Henderson, H. Y. Lee, J. S. Park, J. Jang, S. Jang, T. Jeon, M. O'Mullane, and W. Choe, Nucl. Fusion 55, 063016 (2015).

${ }^{12}$ C. R. Seon, J. S. Jeon, M. S. Cheon, S. Pak, H. G. Lee, P. Bernascolle, and R. Barnsley, Fusion Eng. Des. 109-111, 656-660 (2016).

${ }^{13}$ R. Barnsley, I. H. Coffey et al., Rev. Sci. Instrum. 74, 1969 (2003).

${ }^{14}$ K. D. Lawson, K. M. Aggarwal, I. H. Coffey, F. P. Keenan, M. G. O'Mullane, L. Ryć, J. Zacks, and JET-EFDA Contributors, Plasma Phys. Controlled Fusion 53, 015002 (2011).

${ }^{15}$ T. Pütterich, R. Neu, R. Dux, A. D. Whiteford, M. G. O'Mullane, and ASDEX Upgrade Team, Plasma Phys. Controlled Fusion 50, 085016 (2008).

${ }^{16}$ D. G. Simons, G. W. Fraser, P. A. J. De Korte, J. F. Pearson, and L. De Jong, Nucl. Instrum. Methods Phys. Res., Sect. A 261, 579 (1987).

${ }^{17}$ L. Poletto, A. Boscolo, and G. Tondello, Appl. Opt. 38, 29 (1999).

${ }^{18}$ H. Garnir and P.-H. Lefëbvre, Nucl. Instrum. Methods Phys. Res., Sect. B 235, 530 (2005). 